\title{
VNCOP-B Regimen
}

National Cancer Institute

\section{Source}

National Cancer Institute. VNCOP-B Regimen. NCI Thesaurus. Code C162002.

A chemotherapy regimen consisting of cyclophosphamide, mitoxantrone, vincristine, etoposide, bleomycin, and prednisone that may be used in the treatment of non-Hodgkin lymphoma (NHL). 